\title{
Extraction, purification, characterization and antioxidant activities of polysaccharides from Ramaria botrytis (Pers.) Ricken
}

Hua Li

\begin{abstract}
Background: Ramaria botrytis (Pers.) Ricken, a member of the family Clavariaceae, has been widely prescribed for anti-aging and improving immunity. To extract and purify the polysaccharides, the main constituent of the fruitingbody, from $R$. botrytis and explore antioxidant activities was great significant.

Results: Ramaria botrytis polysaccharides (RBP) was extracted with water at $88.47^{\circ} \mathrm{C}$ for $1.42 \mathrm{~h}$ with a solution to sample ratio of $10.94 \mathrm{~mL} \mathrm{~g}^{-1}$ employing response surface methodology. Four purified fractions, RBP-1, RBP-2, RBP-3, and RBP-4, were obtained from column chromatography of DEAE-52 and Sephadex G-100. Among these four purified fractions, RBP-1, RBP-2, RBP-4 were mainly composed of glucose, while RBP-3 contained $41.36 \%$ mannose and $28.96 \%$ glucose. The molecular weights of RBP-1, RBP-2, RBP-3 and RBP-4 were 6.48, 36.12, 96.72 and 8.34 kDa, respectively. These four fractions are also tested for antioxidant activities in vitro, RBP-4 exhibited strong assay of reducing power and high scavenging activity on DPPH radical, while RBP-3 showed the stronger ability of hydroxyl radical scavenging activity.
\end{abstract}

Conclusions: Response surface methodology was successfully applied to optimize the ultrasonic extraction of polysaccharides from $R$. botrytis. RBP is an efficient natural antioxidant.

Keywords: Ramaria botrytis, Polysaccharides, Purification, Antioxidant activities

\section{Background}

Edible mushrooms commonly used as food, flavoring substances or folk traditional medicines, are well-known for their abundant nutrients: carbohydrates, proteins, vitamins, minerals, characteristic flavour components, and other bioactive components [1]. Meanwhile, Products from wild and cultivated edible mushrooms, have acquired considerable attention toward their biological functions, such as improving immunity, antioxidant, anti-cancer and anti-viral activities due to their functional constituents [2-4].

Extensive studies have been done with the structure and bioactivity mechanism of natural polysaccharides and their conjugates, which have been used in food and medicine for a long time $[5,6]$. Numerous researches

\footnotetext{
*Correspondence: lixian78101@163.com

College of Food Science and Technology, Henan University of Technology, Zhengzhou 450001, China
}

demonstrated that plenty of natural polysaccharides were good at protecting human bodies from oxidative damage in the growth and development of living organism [7-9]. Therefore, natural polysaccharides are considered as a potential resource of novel antioxidants, and the mechanism of polysaccharide are in need of further research $[6$, 10].

Ramaria botrytis (Pers.) Ricken, one of mushrooms widely consumed as edible food especially prevailing Asian countries including China, mainly due to its special favor and rich nutrients. It is known as cauliflower coral and belongs to Clavariaceae [11]. Polysaccharide, water soluble and water insoluble, is one of the most important bioactive substances in $R$. botrytis. Recent research revealed that two water insoluble glucans had been isolated from the alkali extract of the fruit bodies of $R$. botrytis [11]. In this paper, the extraction, purification, characterization and antioxidant activities of 
polysaccharides isolated from $R$. botrytis is described. This study aims to purify fractions of water soluble polysaccharides, analyze their preliminary characteristics and investigate their antioxidant activities.

\section{Experimental procedures Materials and chemicals}

The samples of $R$. botrytis, collected by the author in Ailao mountains, Yunnan Province, China, in August 2013. Identification of the mushrooms was performed by Prof. Li Yu, the academician of Jilin Agricultural University. Removed impurities and cleaned with water, the samples were air-dried to constant weight at $60{ }^{\circ} \mathrm{C}$. Then the dried sample was ground into fine powder and screened through a 40 mesh sieve. The powder was prepared for the subsequent studies.

Analytical grade of 2, 2-diphenyl-1-picryl-hydrazyl (DPPH) and 1, 10-phenanthroline was purchased from the Sigma-Aldrich Trading Limited Corporation (Shanghai, China) and the Kermel Chemical Corporation (Tianjin, China), respectively. Other reagents used in this study were of analytical grade.

\section{Box-Behnken factorial design (BBD) for the extraction of RBP}

Box-Behnken factorial design was used as interaction design to explore the effect of the main independent variables. Based on the preliminary single factor experiment and BBD principle, a three-factor-three-level BBD was employed in this study. Three extraction variables: $\mathrm{X}_{1}$ (water to raw material ratio), $\mathrm{X}_{2}$ (extraction temperature), and $\mathrm{X}_{3}$ (extraction time) (Table 1 ) were viewed as the independent variables, and the purity of the RBP was the dependent variable in this design.

The result of the BBD contained 17 experimental points, including twelve factorial points and five axial points. The five axial points were for pure error estimation in the test. The non-linear quadratic model produced in the response surface by Design Expert 8.0 is shown in Eq. (1) [12]:

$$
y=\beta_{k_{0}}+\sum_{i=1}^{3} \beta_{k_{i}}+\sum_{i=1}^{3} \beta_{k_{i i}} X_{i}^{2}+\sum_{i<j=2}^{3} \beta_{k_{i j}} X_{i} X_{j}
$$

where $\mathrm{y}$ is the dependent variable, $\beta_{k_{0}}$ is the constant, $\beta_{k_{i}}$, $\beta_{k_{i i}}$, and $\beta_{k_{i j}}$ represent the linear regression coefficients of variables, quadratic and interaction terms, respectively; $X_{i}$ and $X_{j}$ are the independent variables wherein $i$ and $j$ are the levels of the independent variables $(i \neq j)$. The regression analysis and analysis of variances (ANOVA) helped predict the polynomial model to investigate complex processes. The fitted polynomial equation, aiming at visualizing the relationship between the response and
Table 1 Independent variables and their levels for the extraction of RBP

\begin{tabular}{llll}
\hline Independent variables & Factor & & \\
\cline { 2 - 4 } & $\mathbf{- 1}$ & $\mathbf{0}$ & $\mathbf{1}$ \\
\hline Water to raw material ratio $(\mathrm{mL} / \mathrm{g})$ & 10 & 15 & 20 \\
Extraction temperature $\left({ }^{\circ} \mathrm{C}\right)$ & 70 & 80 & 90 \\
Extraction time $(\mathrm{h})$ & 1.0 & 1.5 & 2.0 \\
\hline
\end{tabular}

experimental levels of each factor, developed the final response surfaces and deduced the optimum conditions $[13,14]$. The regression coefficients from the regression model generated different dimensional and contour maps. The predicted values, calculated by Statistica (Version8.0, USA), aimed at estimating the statistical significance of the independent variables. The polysaccharide content of crude RBPs was determined by phenol-sulfuric acid method [15].

\section{Analytical method validation}

The total content of polysaccharide in $R$. botrytis was analyzed by phenol-sulfuric acid method using glucose as standard [15]. The regression equation was $Y=0.0124 x-0.0032$ with the correlation coefficient as 0.9926 , where $Y$ represents absorbance, $x$ represents the concentration of glucose or RBP. A linear relationship between the absorbance and the polysaccharide quantity was observed within the range of $0-40 \mu \mathrm{g} \mathrm{mL}^{-1}$, detected at $490 \mathrm{~nm}$ wavelength.

The extraction method was validated in terms of precision and accuracy. The precision was estimated by analyzing the intra-day (repeatability) and inter-day (intermediate) precision variations. The repeatability was evaluated by testing standard solution at three different concentrations $\left(0.05,0.10\right.$ and $\left.0.20 \mathrm{mg} \mathrm{mL}^{-1}\right)$ with five replicates during one day, and the intermediate precision was evaluated by testing standard solution at three different concentrations $\left(0.05,0.10\right.$ and $\left.0.20 \mathrm{mg} \mathrm{mL}^{-1}\right)$ for three days. The accuracy was evaluated with the spiked recovery test. Three different standards $(0.05,0.10$ and $0.20 \mathrm{mg} \mathrm{mL}^{-1}$ ) were added to blank sample separately for further extraction and analysis.

\section{Preparation of crude RBP}

The Sevage solution was adopted to remove the proteins in the crude RBP after extracted under the optimal condition. The deproteinized RBP was extracted with the reaction mixture (chloroform: butyl alcohol, 5:1) for three times. After centrifugation ( $15 \mathrm{~min}, 4000 \mathrm{rpm}$, $20{ }^{\circ} \mathrm{C}$ ), ethanol was added into the supernatant until the final concentration of ethanol was $50 \%$. The mixture was standing at $4{ }^{\circ} \mathrm{C}$ for $18 \mathrm{~h}$, then centrifugal separated 
at $4000 \mathrm{rpm}$ for $15 \mathrm{~min}$. The supernatant was collected and repeated the same procedure until the final concentration of ethanol was $60,75,85$ and $95 \%$. The precipitate was collected, freeze-dried and accurately weighed respectively, for further study.

\section{Purification of RBPs}

Crude RBP was purified sequentially by DEAE-52 cellulose and Sephadex G-100 filtration chromatography according to a previous study with little modifications [16]. In detail, the RBP solution $\left(3 \mathrm{~mL}, 10 \mathrm{mg} \mathrm{mL}^{-1}\right)$ was applied tardily to a column $(2.6 \times 40 \mathrm{~cm})$ of DEAE52 cellulose. The column was stepwise eluted with 0 , $0.1,0.3$ and $0.5 \mathrm{~mol} \mathrm{~L}^{-1} \mathrm{NaCl}$ solutions at a flow rate of $1.0 \mathrm{~mL} \mathrm{~min}^{-1}$. Then the obtained elutes ( $5 \mathrm{~mL}$ per tube) were collected by the automatic collector. According to the phenol-sulfuric acid method, each fraction of polysaccharides of RBP was collected. Repeat the process and collect the same fractions together. Each fraction was concentrated, dialyzed and freeze-dried. The solution $\left(2 \mathrm{~mL}, 30 \mathrm{mg} \mathrm{mL}^{-1}\right)$ of each fraction was further purified through the Sephadex G-100 column $(2.6 \times 60 \mathrm{~cm})$. The elutes were collected automatically eluted with deionized water, then concentrated and freeze-dried for further research.

\section{Characterization of RBP}

The monosaccharide composition of RBP-1, RBP-2, RBP-3 and RBP-4 were analyzed by high performance anion exchange chromatography (Dionex ICS-3000, Sunnyvale, CA, USA) in combination with a carbopac PA-1 ion exchange column $(4 \times 250 \mathrm{~mm})$.

The average molecular weights of polysaccharide fractions were determined by gel permeation chromatography (GPC). Each sample (2.0 $\mathrm{mg})$ was dissolved in distilled water $(2 \mathrm{~mL})$, passed through a $0.45 \mu \mathrm{m}$ filter, and then applied to a column of gel-permeation chromatographic at a flow rate of $0.5 \mathrm{~mL} \mathrm{~min}^{-1}$ [14]. The calibration curve was conducted by reference of the dextrans with various molecular weight (P-400, P-100, P-50, P-10, and $\mathrm{P}-5)$.

\section{Determination of antioxidant activities $D P P H$ radical-scavenging activity}

The DPPH radical-scavenging activity of RBPs was assayed based on a reported method [14] with little modification. A series of sample solutions $(0.2,0.4,0.6,0.8,1.0$ and $1.2 \mathrm{mg} \mathrm{mL}^{-1}$ ) were prepared by dissolving polysaccharide samples into distilled water. DPPH powder was dissolved in ethanol $(0.1 \mathrm{mM})$. Aliquots of $1 \mathrm{~mL}$ of the sample solution and $1 \mathrm{~mL}$ of DPPH solution were mixed until homogeneity in a cuvette and incubated $20 \mathrm{~min}$ in the dark. Then the absorption was measured at $517 \mathrm{~nm}$ to detect the reduction of DPPH in the cuvette. Ascorbic acid was used as a positive standard. The DPPH radical scavenging activity of RBPs was expressed by Eq. (2):

$$
\begin{aligned}
& \text { DPPH radical scavenging activity }(\%) \\
& \quad=\left(1-\frac{A_{1}-A_{3}}{A_{2}}\right) \times 100
\end{aligned}
$$

where $A_{1}$ is the absorbance of the reaction solution which contains $1 \mathrm{~mL}$ of sample and $1 \mathrm{~mL}$ of DPPH solution, $A_{3}$ is the absorbance of the solution including $1 \mathrm{~mL}$ of sample and $1 \mathrm{~mL}$ of ethanol, and $A_{2}$ is the absorbance of the solution including $1 \mathrm{~mL}$ of DPPH and $1 \mathrm{~mL}$ of ethanol.

\section{Hydroxyl radical-scavenging activity}

The assay of hydroxyl radical-scavenging activity of RBPs was carried out according to a reported method described previously [17]. Briefly, $1 \mathrm{~mL}$ of distilled water, $1 \mathrm{~mL}$ of 1,10-phenanthroline $(0.75 \mathrm{mM}), 1 \mathrm{~mL}$ of $\mathrm{Fe}_{2} \mathrm{SO}_{4}$ $(0.75 \mathrm{mM})$ and $1 \mathrm{~mL}$ of $\mathrm{H}_{2} \mathrm{O}_{2}(0.01 \%)$ were dissolved into $2 \mathrm{~mL}$ of phosphate buffer ( $\mathrm{pH}$ 7.4) and mixed thoroughly. Incubated at $37^{\circ} \mathrm{C}$ for $60 \mathrm{~min}$, the mixture solution was used as the blank solution. The control solution was prepared under the similar sequence, only $1 \mathrm{~mL}$ of distilled water instead of $1 \mathrm{~mL}$ of $\mathrm{H}_{2} \mathrm{O}_{2}$. The four fractions of polysaccharides were dissolved in distilled water, yielding a series of sample concentrations $(0.2,0.4,0.6,0.8,1.0$ and $1.2 \mathrm{mg} \mathrm{mL}^{-1}$ ), respectively. According to the same procedure, the sample solution was prepared, wherein $1 \mathrm{~mL}$ of distilled water was replaced by $1 \mathrm{~mL}$ of polysaccharide solution. Then, the absorbance of the blank $\left(\mathrm{B}_{\text {blank }}\right)$, control $\left(\mathrm{B}_{\text {control }}\right)$, and sample solutions $\left(\mathrm{B}_{\text {sample }}\right)$ was determined at $510 \mathrm{~nm}$. The results were calculated by Eq. (3):

$$
\begin{aligned}
& \text { Hydroxyl radical scavenging activity }(\%) \\
& =\frac{B_{\text {sample }}-\mathrm{B}_{\text {blank }}}{B_{\text {control }}-\mathrm{B}_{\text {blank }}} \times 100
\end{aligned}
$$

\section{Reducing power}

The reducing power was determined by the method [18] with some modifications. The four RBPs were dissolved in distilled water to form various sample solutions $(0.5$, 1.0, 1.5, 2.0, 2.5 and $\left.3.0 \mathrm{mg} \mathrm{mL}^{-1}\right)$. A volume of $2 \mathrm{~mL}$ sample solution was added into $2.5 \mathrm{~mL}$ phosphate buffer $(0.2 \mathrm{M}, \mathrm{pH} 6.6)$ and $2.5 \mathrm{~mL}$ of potassium ferricyanide (1\%, $\mathrm{w} / \mathrm{v})$. Incubated at $50{ }^{\circ} \mathrm{C}$ for $20 \mathrm{~min}, 2.5 \mathrm{~mL}$ of trichloroacetic acid (TCA) was added to the mixture and centrifuged at $3000 \mathrm{rpm}$ for $10 \mathrm{~min}$. The final mixture solution was formed by adding $2.5 \mathrm{~mL}$ distilled water and $0.5 \mathrm{~mL}$ ferric chloride $(0.1 \%, \mathrm{w} / \mathrm{v})$ to $2.5 \mathrm{~mL}$ of the supernatant. The absorbance of the reaction mixture was measured at $700 \mathrm{~nm}$. Ascorbic acid was used as the positive control. A higher absorbance indicates a stronger reducing power of the sample. 


\section{Results and discussion}

\section{Optimization for the extraction parameters of RBP} Model fitting preliminary

Relying on the 17 experimental points designed by the BBD (Design Expert 8.0, USA), the corresponding yield of RBP were obtained according to the preliminary standard curve. The yield of RBP ranged from 5.97 to 9.90\% (Table 2). The correlation between response variables and test variables was expressed by the following second-order polynomial equation [19]:

$$
\begin{aligned}
Y= & 8.81+0.27 X_{1}+1.61 X_{2}+0.21 X_{3}+0.075 X_{1} X_{2} \\
& +0.12 X_{1} X_{3}+0.15 X_{2} X_{3}-0.81 X_{1}^{2} \\
& -0.13 X_{2}^{2}-0.78 X_{3}^{2}
\end{aligned}
$$

where $Y$ represents the yield of RBP (\%), $X_{1}, X_{2}$ and $X_{3}$ represent ratio of water to solid, extraction temperature and extraction time, respectively.

The results of the analysis of variance (ANOVA) for the quadratic regression model were shown in Table 3. The purity coefficients $\left(\mathrm{R}^{2}\right)$ of the determination was 0.9749 , which indicated that only $1.30 \%$ of the total variance was not explained by the model. At the same time, the adjusted determination coefficient (adj- $\left.R^{2}=0.9626\right)$, which was very close to $R^{2}$, which demonstrated the model was extremely significant. This result showed high consistency between the experimental values and theoretical values predicted by the polynomial regression model. The $p$ values were able to confirm the significance
Table 3 ANOVA for the quadratic regression model in BBD

\begin{tabular}{lcccrr}
\hline Source & Sum of squares & DF & Mean squares & $\boldsymbol{F}$ value & $\boldsymbol{p}$ value \\
\hline Model & 27.31 & 9 & 3.03 & 30.20 & $<0.0001$ \\
$X_{1}$ & 0.60 & 1 & 0.60 & 5.97 & 0.0446 \\
$X_{2}$ & 20.35 & 1 & 20.35 & 202.53 & $<0.0001$ \\
$X_{3}$ & 0.34 & 1 & 0.34 & 3.39 & 0.1083 \\
$X_{1} X_{2}$ & 0.022 & 1 & 0.022 & 0.22 & 0.6505 \\
$X_{1} X_{3}$ & 0.06 & 1 & 0.06 & 0.60 & 0.4649 \\
$X_{2} X_{3}$ & 0.09 & 1 & 0.09 & 0.90 & 0.3755 \\
$X_{1}^{2}$ & 2.81 & 1 & 2.81 & 27.95 & 0.0011 \\
$X_{2}^{2}$ & 0.07 & 1 & 0.07 & 0.70 & 0.4304 \\
$X_{3}^{2}$ & 2.54 & 1 & 2.54 & 25.28 & 0.0015 \\
Residual & 0.70 & 7 & 0.10 & & \\
Lack of fit & 0.38 & 3 & 0.13 & 1.54 & 0.3336 \\
Pure error & 0.33 & 4 & 0.081 & & \\
Cor total & 28.01 & 16 & & & \\
$\mathrm{R}^{2}$ & 0.9749 & & Adj-R & & \\
\hline
\end{tabular}

of each coefficient, which in turn may indicated interaction patterns among the variables [14]. The corresponding coefficient was more significant if the $p$ value was smaller. Accordingly, the model was extremely significant $(p<0.05)$. Meanwhile, $X_{1}, X_{3}, X_{1}^{2}, X_{2}^{2}$ were significantly different $(p<0.05)$, while $X_{2}, X_{3}^{2}, X_{1} X_{2}, X_{1} X_{3}$ and $X_{2} X_{3}$ were not significantly different $(p>0.05)$. The parameter, lack of fit, was used to express the difference between the model and the experiment. It was beneficial to the model

\begin{tabular}{|c|c|c|c|c|c|}
\hline Run & $\begin{array}{l}X_{1} / \text { water to raw } \\
\text { material ratio }\left(\mathrm{mL} \mathrm{g}^{-1}\right)\end{array}$ & $\begin{array}{l}X_{2} \text { /extraction } \\
\text { temperature }\left({ }^{\circ} \mathrm{C}\right)\end{array}$ & $\begin{array}{l}X_{3} \text { /extraction } \\
\text { time }(\mathrm{h})\end{array}$ & $\begin{array}{l}\text { Extraction } \\
\text { yield (\%) }\end{array}$ & $\begin{array}{l}\text { Predicted } \\
\text { yield }(\%)\end{array}$ \\
\hline 1 & $10(-1)$ & $90(1)$ & $1.5(0)$ & 9.10 & 9.11 \\
\hline 2 & $20(1)$ & $70(-1)$ & 1.5 & 6.47 & 6.46 \\
\hline 3 & 20 & $80(0)$ & $2.0(1)$ & 7.97 & 7.82 \\
\hline 4 & $15(0)$ & 80 & 1.5 & 8.57 & 8.81 \\
\hline 5 & 15 & 80 & 1.5 & 8.45 & 8.81 \\
\hline 6 & 15 & 70 & $1.0(-1)$ & 6.50 & 6.25 \\
\hline 7 & 20 & 90 & 1.5 & 9.90 & 9.80 \\
\hline 8 & 15 & 80 & 1.5 & 8.87 & 8.81 \\
\hline 9 & 15 & 70 & 2.0 & 6.20 & 6.36 \\
\hline 10 & 15 & 80 & 1.5 & 9.07 & 8.81 \\
\hline 11 & 15 & 90 & 2.0 & 9.60 & 9.85 \\
\hline 12 & 10 & 80 & 1.0 & 6.70 & 6.86 \\
\hline 13 & 10 & 80 & 2.0 & 7.28 & 7.02 \\
\hline 14 & 10 & 70 & 1.5 & 5.97 & 6.07 \\
\hline 15 & 15 & 90 & 1.0 & 9.30 & 9.14 \\
\hline 16 & 20 & 80 & 1.0 & 6.90 & 7.16 \\
\hline 17 & 15 & 80 & 1.5 & 9.07 & 8.81 \\
\hline
\end{tabular}
without any significance in the lack of fit.

Table 2 The Box-Behnken design and the yield of Ramaria botrytis polysaccharide 


\section{Optimization for the extraction of RBP}

Generated by Design-Expert, these three-dimensional plots and their corresponding contour plots (Fig. 1), which were graphical representations of the quadratic regression equation, presented the interactions of three variables (Table 1) better. By keeping another variable at its zero level, these types of contour plots visualized whether the interactions between the two variables were significant or not. According to that method, these 3D response surfaces and $2 \mathrm{D}$ contour plots provided the significance degree between each two variables. Correspondingly, they facilitated the generation of the optimum experimental combination. The optimum experimental variables for the extraction of RBP were as follows: extraction temperature $88.47^{\circ} \mathrm{C}$, extraction time $1.42 \mathrm{~h}$ and ratio of water to solid $10.94 \mathrm{~mL} \mathrm{~g}^{-1}$. Among the three effective parameters, the extraction time was the most significant factor during the extraction of RBP. Between the other parameters, the ratio of water to solid was more significant than the extraction temperature.

\section{Verification of the model}

The relative standard deviation (RSD) value of repeatability was $3.25 \%$, and the RSD value of intermediate precision was $2.68 \%$, which showed the precision of instruments was good. The spiked recoveries of glucose were $91.20-104.30 \%$. In summary, the method was effective and reliable. The polysaccharide yield was $9.08 \%$ according to the optimal extraction condition, in which the extraction temperature $90{ }^{\circ} \mathrm{C}$, extraction time $1.5 \mathrm{~h}$ and ratio of water to solid $11.00 \mathrm{~mL} \mathrm{~g}^{-1}$.

\section{Fractional precipitation of polysaccharides}

The yield of the precipitation was 58.06, 12.08, 18.78 and $11.08 \%$, as the concentration of ethanol $50,75,85$ and $95 \%$. No precipitate appeared when the concentration of ethanol was up to $95 \%$. From the yield, the polysaccharide collected with the concentration of ethanol $50 \%$ was the main component and was acted as crude polysaccharide to purify further.

\section{Purification of crude RBP}

Crude polysaccharide of $20 \mathrm{~g}$ was purified firstly by a DEAE-52 cellulose column, which could isolate polysaccharides with negative charges from the crude polysaccharide. After the elution with $0,0.1,0.3$ and $0.5 \mathrm{~mol} \mathrm{~L}^{-1}$ $\mathrm{NaCl}$ solutions, four independent peaks in Fig. 2 appeared using the phenol-sulfuric acid method. Each fraction was collected, concentrated, dialyzed, freezedried and loaded to a column of Sephadex G-100, which was eluted with deionized water. Finally, each fraction produced a single elution peak (Fig. 3a-d), which defined as RBP-1, RBP-2, RBP-3 and RBP-4, respectively.

\section{Characterization of RBP \\ Monosaccharide composition of RBP}

The monosaccharide composition of RBP-1, RBP-2, RBP-3 and RBP-4 was analyzed by high performance anion exchange chromatography and a carbopac PA-1 ion exchange column. From results shown in Table 4, different purified fractions had different monosaccharide compositions. RBP-1 contained only two kinds of monosaccharides: gluctose $(88.24 \%)$ and galactose (11.76\%). RBP-2 was mainly composed of glucose. Meanwhile, the contents of galactose, mannose and xylose in RBP-2 were much lower than those in RBP-1 and RBP-4. Little arabinose only existed in RBP-3.

\section{Molecular weight determination of RBPs}

The molecular weight of RBP-1, RBP-2, RBP-3, and RBP-4 was determined by GPC method. According to the different molecular weight of dextran standards, the average molecular weights of RBP-1, RBP-2, RBP-3 and RBP-4 were $6.48,36.12,96.72$ and $8.34 \mathrm{kDa}$, respectively.

\section{Antioxidant activity in vitro of RBP Scavenging activity on DPPH radical of RBP}

Acted as hydrogen donors, DPPH, which owns a proton free radical with a characteristic absorption, has been widely used to evaluate antioxidant activity of polysaccharides $[4,8]$. The scavenging ability of four polysaccharides for DPPH. radical is shown in Fig. 4a and ascorbic acid was the positive control. The results indicated that RBP-4, RBP-3 and RBP-3 displayed concentration dependent radical scavenging effects although weaker than that of $\mathrm{Vc}_{\mathrm{c}}$ in the same concentration, and the order was RBP-4 > RBP-3 > RBP-1 > RBP-2. Along with the increased concentration of each polysaccharide, the DPPH. scavenging ability increased. At $1.4 \mathrm{mg} \mathrm{mL}^{-1}$ of RBP-4, the DPPH scavenging percentage was $82.67 \%$, and less than the ascorbic acid control 15\%, while the scavenging percentage of RBP3, RBP1and RBP-2 was 74.01, 44.33 and $14.67 \%$. RBP-2 showed lowest effect on DPPH, perhaps due to its special structure, that should be studied further.

\section{Assay of hydroxyl radical scavenging activity}

The hydroxyl radical, which has high reactivity and a very short half-life of approximately $10^{-9} \mathrm{~s}$ in vivo, is the most reactive and dangerous compound generated through the Fenton reaction to organisms [8]. The hydroxyl radical-scavenging activity of RBP-1, RBP-2, RBP-3, RBP-4 and ascorbic acid determined at $510 \mathrm{~nm}$ were depicted in Fig. 4b. The results showed the scavenging activity of RBP-3 was higher than RBP-4, RBP2, RBP-1, but lower than ascorbic acid. The hydroxyl radical-scavenging activity of ascorbic acid and all the 
a

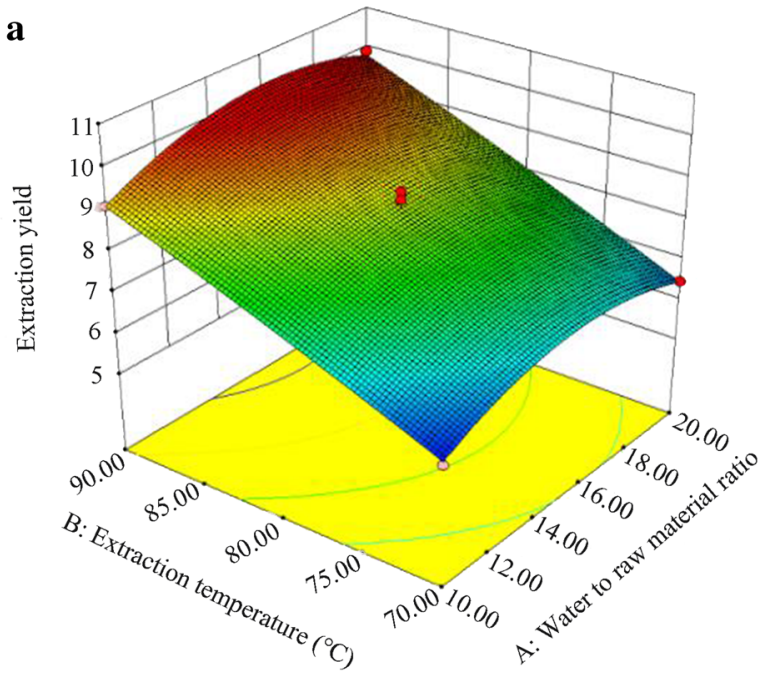

c
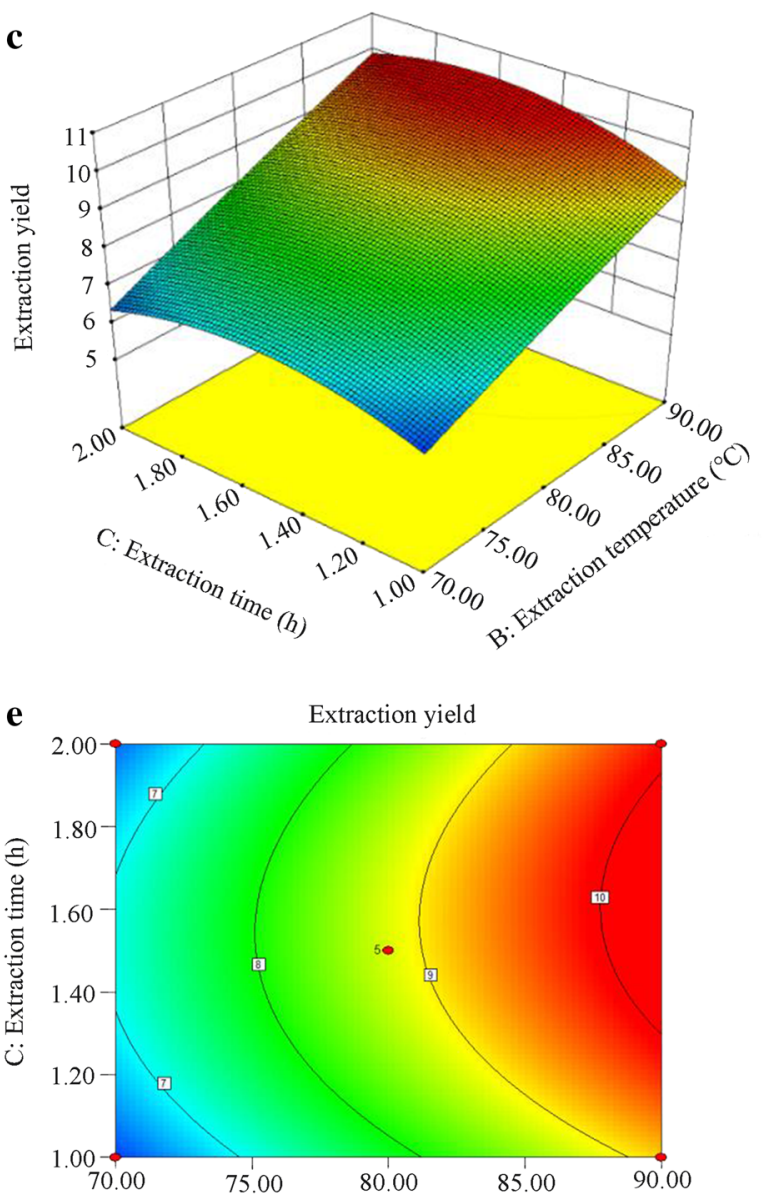

B: Extraction temperature $\left({ }^{\circ} \mathrm{C}\right)$

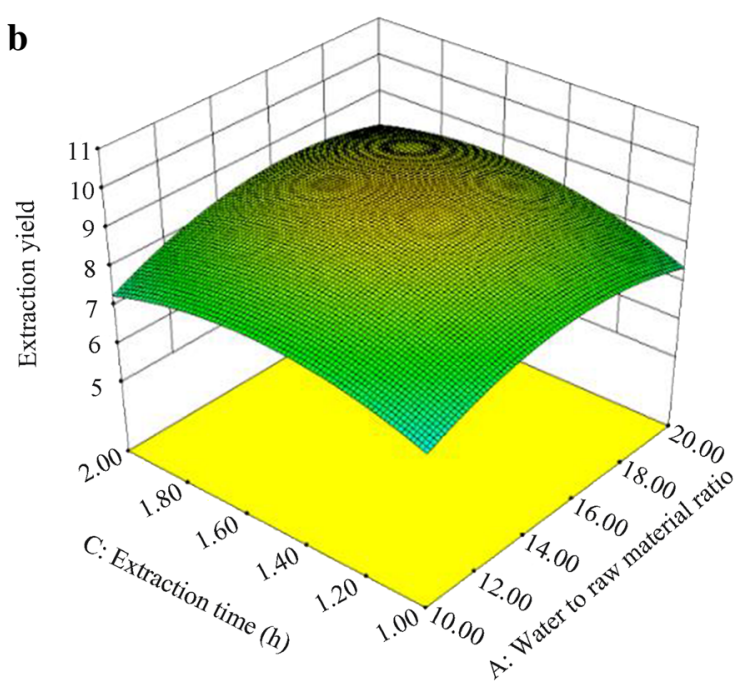

d

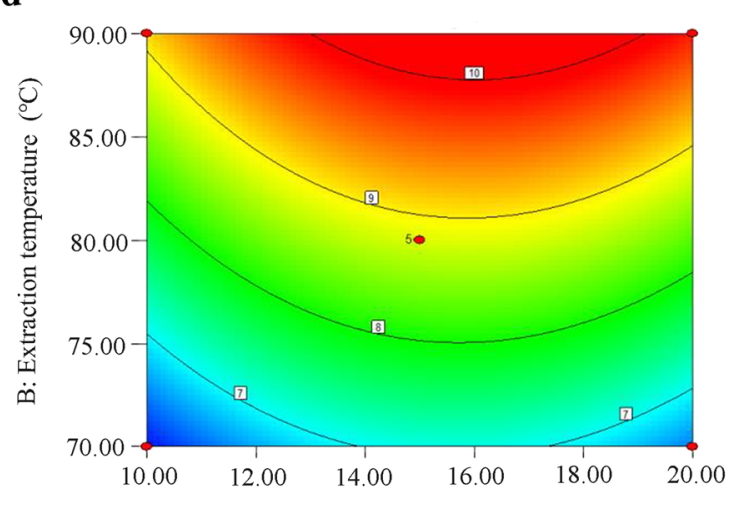

A: Water to raw material ratio

f

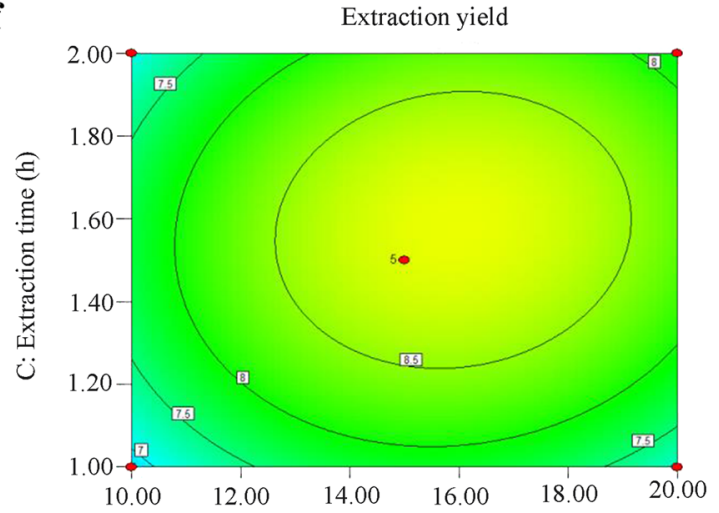

A: Water to raw material ratio

Fig. 1 Three-dimensional plots $(\mathbf{a}, \mathbf{b}, \mathbf{c})$ and their corresponding contour plots $(\mathbf{d}, \mathbf{e}, \mathbf{f})$ showing the effect of each two independent variables on the yield of RBP 


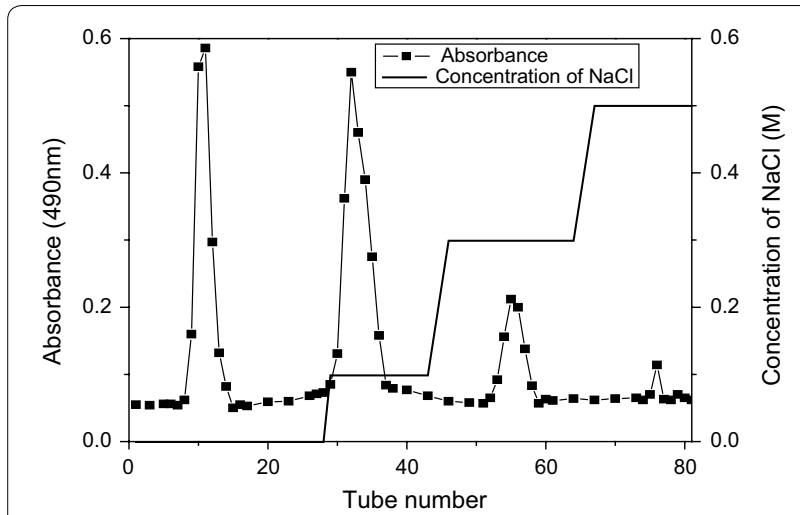

Fig. $20,0.1,0.3,0.5 \mathrm{M} \mathrm{NaCl}$ stepwise elution curve of crude RBP by DEAE-52 column

polysaccharides increased gradually as their concentrations increased. With the increase of amount in the range of $0-1.2 \mathrm{mg} \mathrm{mL}^{-1}$, hydroxyl radical-scavenging
Table 4 Monosaccharide composition for RBP-1, RBP-2, RBP-3, RBP-4

\begin{tabular}{lcccc}
\hline Samples & RBP-1 & RBP-2 & RBP-3 & RBP-4 \\
\hline Weight (g) & 4.42 & 8.87 & 1.56 & 0.35 \\
Glucose & $88.24 \%$ & $95.42 \%$ & $28.96 \%$ & $65.62 \%$ \\
Galactose & $11.76 \%$ & $1.94 \%$ & $14.37 \%$ & $15.15 \%$ \\
Mannose & - & $1.98 \%$ & $41.36 \%$ & - \\
Arabinose & - & - & $0.31 \%$ & $15.28 \%$ \\
Xylose & - & $0.66 \%$ & $15.01 \%$ & $3.95 \%$ \\
\hline
\end{tabular}

- , not detected

activityof each compound increased, whereas the activity of RBP-3 (90\%) was approximatelythe same as ascorbic acid $(95.33 \%)$ at the concentration of $1.2 \mathrm{mg} \mathrm{mL}^{-1}$.

\section{Assay of reducing power}

Served as a significant indicator of its potential antioxidant activity, the reducing power of a compound may
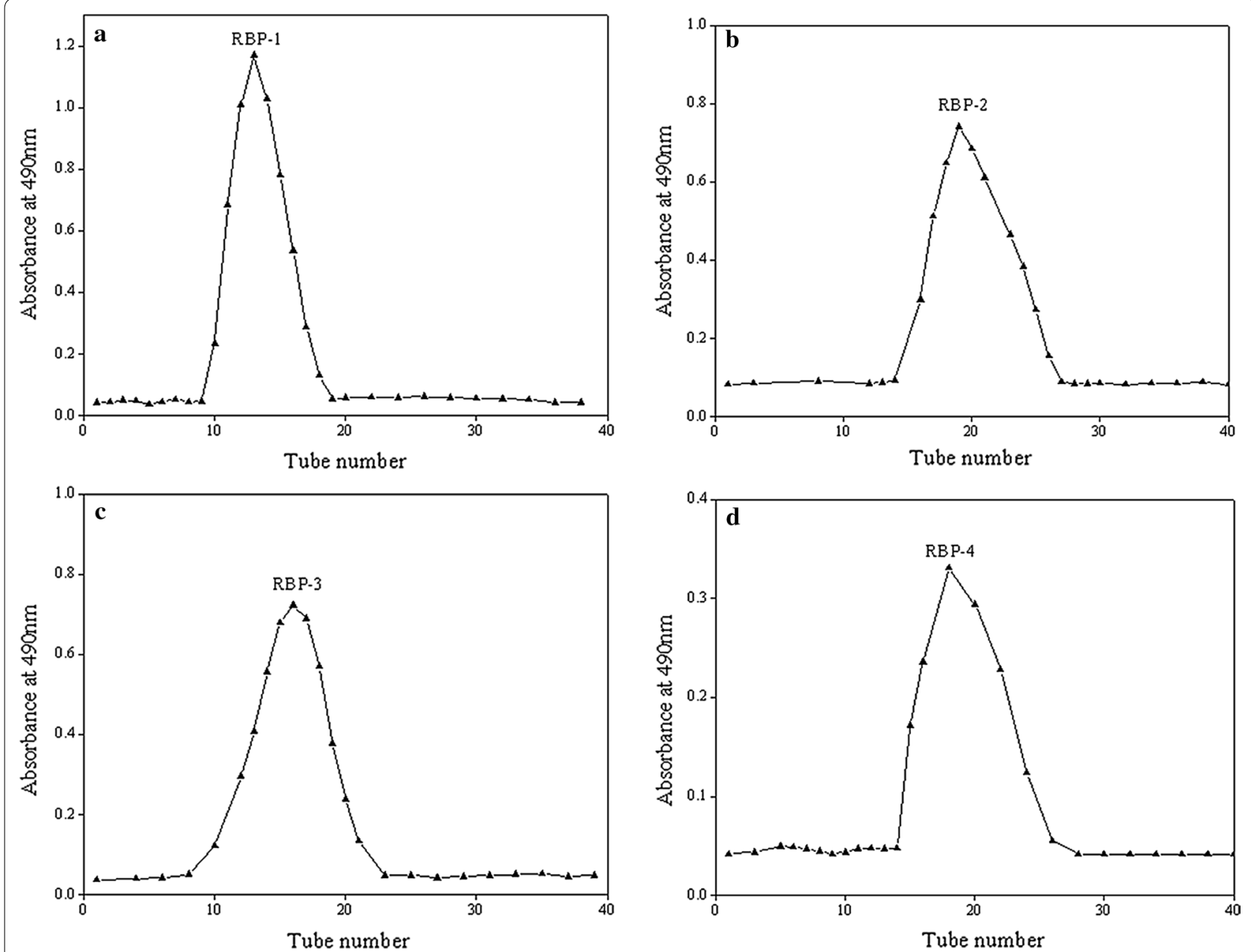

Fig. 3 Distilled water elution curve of each fraction a RBP-1, b RBP-2, c RBP-3, d RBP-4 on Sephadex G-100 column 

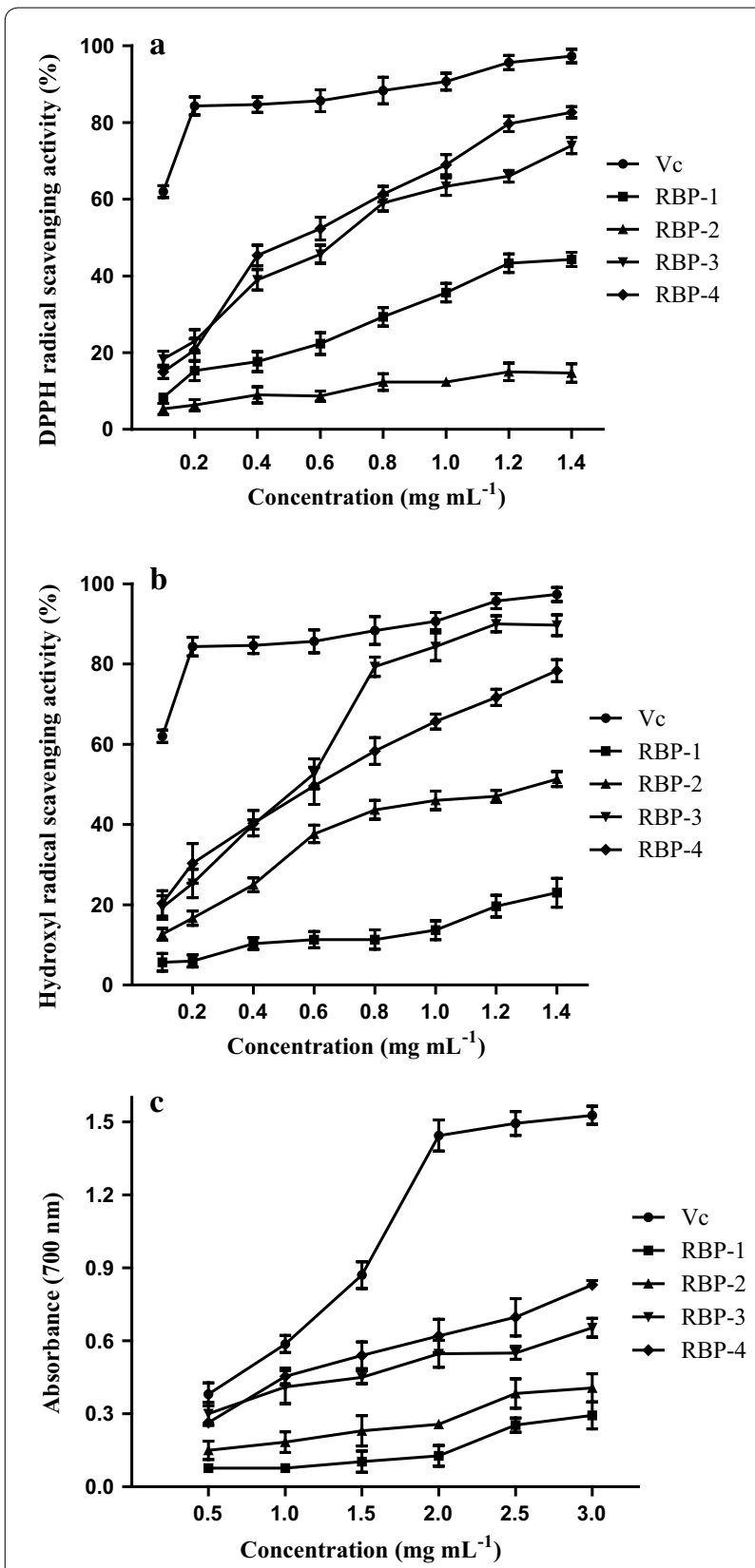

Fig. 4 Scavenging activities on a DPPH radical, b hydroxyl radical, c reducing power assay for RBP-1, RBP-2, RBP-3, RBP-4 at various concentrations. Data shown were mean \pm standard deviation $(n=3)$

directly reflect the production condition of electron donor [20, 21]. The reducing power of RBP-1, RBP-2, RBP-3, RBP-4 and ascorbic acid determined at $700 \mathrm{~nm}$ is depicted in Fig. 4c. Ascorbic acid is a well-recognized reducing agent. As shown in the figure, the reducing power of ascorbic acid increased quickly as the concentration increased from 0.2 to $1.2 \mathrm{mg} \mathrm{mL}^{-1}$. All four samples showed higher reducing power with the increasing of their concentrations, but much lower than ascorbic acid. RBP-4 had the strongest reducing power among the four fractions.

\section{Conclusion}

It can be concluded that the water-soluble and purified polysaccharides from the sporocarp of $R$. botrytis could be obtained with the optimized method. Firstly, The BBD method provided the optimal extraction condition of the crude polysaccharide. And the crude polysaccharide was eluted and purified by two column chromatographies of DEAE-52 and Sephadex G-100 successively. Four purified fractions of polysaccharides, RBP-1, RBP-2, RBP-3 and RBP-4 were obtained in this study, which average molecular weights were $6.48,36.12,96.72$ and $8.34 \mathrm{kDa}$, respectively. Moreover, RBP-1, RBP-2, RBP-4 were mainly composed of glucose, with a percentage of $88.24,95.42$ and $65.62 \%$, respectively; while RBP-3 contained $41.36 \%$ mannose, $28.96 \%$ glucose, $15.01 \%$ xylose and $14.37 \%$ galactose. Furthermore, the antioxidant activity tests showed that RBP-4 had strong assay of reducing power and high scavenging activity on DPPH radical, while RBP-3 exhibited the strongest ability of hydroxyl radical scavenging activity. All the results implied that RBP could be a promising new natural antioxidant in food industry or drug therapies.

\section{Acknowledgements}

This work was supported by the National Natural Science Foundation of China (31401548), Special Fund for Agro-scientific Research in the Public Interest (No. 201303070) and the fundamental research funds for special projects of Henan University of Technology (2014YWQQ04).

\section{Competing interests}

The author declares that she has no competing interests.

Received: 15 July 2016 Accepted: 9 March 2017

Published online: 16 March 2017

\section{References}

1. Kalac P (2009) Chemical composition and nutritional value of European species of wild growing mushrooms: a review. Food Chem 113:9-16

2. Unekwu HR, Audu JA, Makun MH, Chidi EE (2014) Phytochemical screening and antioxidant activity of methanolic extract of selected wild edible Nigerian mushrooms. Asian Pac J Trop Dis 4:153-157

3. Moon SM, Kim JS, Kim HJ, Choi MS, Park BR, Kim SG, Ahn H, Chun HS, Shin YK, Kim JJ, Kim DK, Lee SY, Seo YW, Kim YH, Kim CS (2014) Purification and characterization of a novel fibrinolytic a chymotrypsin like serine metalloprotease from the edible mushroom, Lyophyllum shimeji. J Biosci Bioeng 117:544-550

4. Zhang YY, Li S, Wang XH, Zhang L, Cheung PCK (2011) Advances in lentinan: isolation, structure, chain conformation and bioactivities. Food Hydrocoll 25:196-206

5. Wang QJ, Fang YZ (2004) Analysis of sugars in traditional Chinese drugs. J Chromatogr B 812:309-324

6. Zhang M, Wang F, Liu R, Tang XL, Zhang Q, Zhang ZS (2014) Effects of superfine grinding on physicochemical and antioxidant properties of Lycium barbarum polysaccharides. LWT-Food Sci Technol 58:594-601 
7. Xu HS, Wu YW, Xu SF, Sun HX, Chen FY, Yao L (2009) Antitumor and immunomodulatory activity of polysaccharides from the roots of Actinidia eriantha. J Ethnopharmacol 125:310-317

8. Zhang T, Tian Y, Jiang B, Miao M, Mu WM (2014) Purification, preliminary structural characterization and in vitro antioxidant activity of polysaccharides from Acanthus ilicifolius. LWT-Food Sci Technol 56:9-14

9. Chen TQ, Wu YB, Wu JG, Ma L, Dong ZH, Wu JZ (2014) Efficient extraction technology of antioxidant crude polysaccharides from Ganoderma lucidum (Lingzhi), ultrasonic-circulating extraction integrating with superfine- pulverization. J Taiwan Inst Chem E 45:57-62

10. Tang XH, Yan LF, Gao J, Yang XL, Xu YX, Ge HY, Yang HD (2012) Antitumor and immunomodulatory activity of polysaccharides from the root of Limonium sinense Kuntze. Int J Biol Macromol 51:1134-1139

11. Bhanja SK, Rout D, Patra P, Sen IK, Nandanet CK, Islam SI (2014) Waterinsoluble glucans from the edible fungus Ramaria botrytis. Bioact Carbohyd Diet Fibre 3:52-58

12. Jiang GX, Wen LR, Chen F, Wu FW, Lin S, Yang B, Jiang YM (2013) Structural characteristics and antioxidant activities of polysaccharides from longan seed. Carbohyd Polym 92:758-764

13. Lu CH, Engelmann NJ, Lila MA, Erdman JW (2008) Optimization of lycopene extraction from tomato cell suspension culture by response surface. Agr Food Chem 56:7710-7714

14. You QH, Yin XL, Zhang SN, Jiang ZH (2014) Extraction, purification, and antioxidant activities of polysaccharides from Tricholoma mongolicum Imai. Carbohyd Polym 99:1-10
15. Dubois M, Gilles KA, Hamilton JK, Rebers P, Smith F (1956) Colorimetric method for determination of sugars and related substances. Anal Chem 28:350-356

16. Qiao DL, Hu B, Gan D, Sun Y, Ye H, Zeng XX (2009) Extraction optimized by using response surface methodology, purification and preliminary characterization of polysaccharides from Hyriopsis cumingii. Carbohyd Polym 76:422-429

17. Wu WL, Zhu YT, Zhang L, Yang RW, Zhou YH (2012) Extraction, preliminary structural characterization, and antioxidant activities of polysaccharides from Salvia miltiorrhiza Bunge. Carbohyd Polym 87:1348-1353

18. Oyaizu M (1986) Studies on products of browning reaction: antioxidant activities of products browning reaction prepared from glucosamine. Jpn J Nutr 44:307-313

19. Jia XJ, Ding CB, Yuan S, Zhang ZW, Chen YE, Du L, Yuan M (2014) Extraction, purification and characterization of polysaccharides from Hawk Tea. Carbohyd Polym 99:319-324

20. Meir S, Kanner J, Akiri B, Hadas SP (1995) Determination and involvement of aqueous reducing compounds in oxidative defense systems of various senescing leaves. J Agric Food Chem 43:1813-1819

21. Chen GT, Ma XM, Liu ST, Liao YL, Zhao GQ (2012) Isolation, purification and antioxidant activities of polysaccharides from Grifola frondosa. Carbohyd Polym 89:61-66

\section{Submit your manuscript to a SpringerOpen ${ }^{\circ}$ journal and benefit from:}

- Convenient online submission

- Rigorous peer review

- Immediate publication on acceptance

- Open access: articles freely available online

- High visibility within the field

- Retaining the copyright to your article

Submit your next manuscript at $\boldsymbol{\nabla}$ springeropen.com 